\title{
Methodological Advances in Cross-National Research: Multilevel Challenges and Solutions*
}

\author{
Melinda Mills Patrick Präg \\ Department of Sociology and Nuffield College, \\ University of Oxford, United Kingdom
}

April 2015

Since its inception, the European Sociological Review (ESR) has encouraged 'cross-national comparative work which concentrates on or includes European societies' (Mayer et al., 1985). Although our focus is not merely on papers of a crossnational nature, we have published a considerable number of such studies. Another aim of ESR is to further the more general development of sociology by publishing theoretical and methodological articles where these have a direct relevance for sociological research. A recent example of a prominent methodological study in ESR was the article by Mood (2010), which has-judging from the nearly 300 citations it has already received in SSCI-listed journals alone - had considerable impact on the way logistic regression is practiced (or not) in contemporary social science research.

The Special Section in this volume of ESR tackles another fundamental methodological issue in sociology. The section consists of two methodological papers that we hope will, once again, have a considerable impact on the discipline. The articles raise important concerns about the way much of current cross-national research is conducted. In the first contribution, Bryan and Jenkins (2016) address problems of the use of the multilevel (random effects) model in cross-national analyses. They

*Published in February 2016 in European Sociological Review 32(1), pp. 1-2, doi:10.1093/esr/jcw009. Editorial to the Special Section containing the articles by Bryan and Jenkins (2016) and by Schmidt-Catran and Fairbrother (2016).

Melinda C. Mills is the Editor-in-Chief of European Sociological Review. Patrick Präg is the Deputy Editor of European Sociological Review. 
likewise address the common question: How many countries are required to correctly estimate a multilevel model? They conclude that more than a fifth of all articles published in ESR between 2005 and 2012 used multilevel models of individuals nested in countries, and that in more than half of those articles random effects models where used. Data sets typically used in these applications - such as the European Social Survey or the International Social Survey Program-usually provide information on only a limited number of countries. This lack of degrees of freedom at the country level impedes robust estimates of 'country effects' or, in other words, country-level characteristics that are related to outcomes at the individual level. From a set of Monte Carlo simulations, they conclude that 25+ countries for linear random effects models and 30 countries for logit models are the bare minimum for estimating country effects. Ignoring these critical numbers leads to imprecise estimates, and too often country effects will be detected where there are none. We hope and anticipate that this article will serve as a guideline of best practices in cross-national comparative research using multilevel models.

In the second contribution to this Special Section, Schmidt-Catran and Fairbrother (2016) add a further caveat to the random effects model. The abovementioned multi-country data sets are increasingly available for multiple time points, forming panels not of individuals that are followed over time, but rather panels of countries (and individuals in them) observed at multiple time points. ESR authors have readily capitalized on this analytical potential of longitudinal surveys. SchmidtCatran and Fairbrother identify 17 articles that have analyzed such data since 2001. There are, however, important analytic decisions that need to be made with such research designs. Using Monte Carlo simulations and useful illustrative examples, Schmidt-Catran and Fairbrother show how omitting random effects at potentially relevant levels can lead to the wrong conclusions, again often in detecting effects that do not exist.

Our hope is that this Special Section facilitates current and future cross-national comparative research. The contributions go beyond the truisms that no advanced statistical method can replace careful inspection and description of research data and that robustness checks are always warranted. Both Bryan and Jenkins and Schmidt-Catran and Fairbrother offer valuable and clear guidelines for multilevel research endeavors in their articles. We also urge readers to access the remarkably rich Supplementary Materials that are provided online as companions to these articles on the ESR website. Bryan and Jenkins review numerous techniques that can 
supplement or replace the random effects model when warranted by the research goal or the nature of the data at hand.

As an added value, we would like to draw to your attention that both articles provide readers with the code necessary for replicating their simulations in the Supplementary Materials available on the ESR website. We encourage other authors who publish quantitative analyses using publicly accessible data sets to follow suit.

\section{References}

Bryan, Mark L. and Stephen P. Jenkins, 2016. 'Multilevel Modeling of Country Effects. A Cautionary Tale.' European Sociological Review 32(1): 3-22. doi: 10.1093/esr/jcv059.

Mayer, Karl-Ulrich, John H. Goldthorpe, and Stein Ringen, 1985. 'Editorial Foreword.' European Sociological Review 1(1): i-ii.

Mood, Carina, 2010. 'Logistic Regression. Why We Cannot Do What We Think We Can Do, and What We Can Do About It.' European Sociological Review 26(1): 67-82. doi: 10.1093/esr/jcp006.

Schmidt-Catran, Alexander and Malcolm Fairbrother, 2016. 'The Random Effects in Multilevel Models. Getting Them Wrong and Getting Them Right.' European Sociological Review 32(1): 23-38. doi: $10.1093 /$ esr/jcv090. 